\title{
Periodismo alternativo, alfabetización y co-construcción del imaginario social de la discapacidad en los juegos de Río 2016
}

Alternative journalism, literacy and co-construction of the social imaginary of disability in the Rio 2016 games

Jornalismo alternativo, alfabetização e co-construção do imaginário social de la discapacidad nos jogos do Rio 2016

Sandra MELÉNDEZ-LABRADOR

Universidad del Norte, Colombia, Co-fundadora y directora del Observatorio Latinoamericano de Discapacidad y Comunicación smelendezcom@gmail.com

Chasqui. Revista Latinoamericana de Comunicación

N. ${ }^{\circ}$ 146, abril-julio 2021 (Sección Monográfico, pp. 119.136)

ISSN 1390-1079 / e-ISSN 1390-924X

Ecuador: CIESPAL

Recibido: 08-12-2020/Aprobado:05-02-2021 


\title{
Resumen
}

En esta investigación se analizó la manera como el periodismo alternativo presentó la relación deporte y discapacidad desde una perspectiva progresista, al tiempo que alentó una co-construcción de (auto) representaciones basadas en este modelo. A través de observación participante en los Juegos Paralímpicos de Río 2016 y el análisis textual de las noticias y entrevistas a todos los deportistas paralímpicos colombianos, se logró determinar que estos medios construyeron discursos sobre paralimpismo que rompieron los estereotipos centrados en la corporeidad y que se enfocaron en el alto rendimiento deportivo de los atletas. Se concluyó que este ejercicio periodístico, basado en un enfoque participativo y en la alfabetización del modelo progresista de representación mediática de la discapacidad, puede cumplir un papel transformador del imaginario social sobre las personas con diversidad funcional, consolidando nuevas narrativas e imágenes positivas, de empoderamiento e inclusión, que son consecuentes con la lucha por los derechos de esta población.

Palabras clave: periodismo alternativo; discapacidad; paralímpicos; alfabetización; participación

\begin{abstract}
This research analyzed how alternative journalism presented the relationship between sport and disability from a progressive perspective, while encouraging a co-construction (self-) representation based on this model. Through participant observation at the Rio 2016 Paralympic Games, textual analysis of the news and interviews with all Colombian Paralympic athletes, it was determined that these media constructed discourses on Paralympics that broke the stereotypes centered on corporeality and focused on the high sports performance of the athletes. It was concluded that this journalistic exercise, based on a participatory approach and on the literacy of the progressive model of media representation of disability, can play a transforming role in the social imaginary about people with functional diversity, consolidating new narratives and positive images of empowerment and inclusion, which are consistent with the struggle for the rights of this population.
\end{abstract}

Key words: alternative journalism; disability media; disability; paralympics; literacy; participation

\section{Resumo}

Esta pesquisa analisou como ojornalismo alternativo apresentava a relação entre esporte e deficiência sob uma perspectiva progressiva, ao mesmo tempo em que incentivava uma co-construção (auto) representações baseadas neste modelo. Através da observação dos participantes nos Jogos Paraolímpicos Rio 2016, 
análise textual das notícias e entrevistas com todos os atletas paraolímpicos colombianos, foi determinado que estes meios de comunicação construíram discursos sobre paraolímpicos que quebraram os estereótipos centrados na corporeidade e focados no alto desempenho esportivo dos atletas. Concluiu-se que este exercício jornalístico, baseado numa abordagem participativa e na alfabetização do modelo progressivo de representação midiática da deficiência, pode desempenhar um papel transformador no imaginário social sobre pessoas com diversidade funcional, consolidando novas narrativas e imagens positivas de empoderamento e inclusão, que são consistentes com a luta pelos direitos desta população.

Palavras-chave: jornalismo alternativo; mídia; deficiência; paralimpíadas; alfabetização; participacão

\section{Introducción}

Los Juegos Paralímpicos (en adelante JJPP) se han convertido en la ventana mediática de promoción deimágenes sobre discapacidad, teniendo en cuenta que se trata del tercer evento deportivo más mediatizado a escala mundial después del mundial de fútbol y las olimpiadas. Como afirman McPherson, O’Donnell, McGillivray y Misener (2016, p. 662) "los principales eventos deportivos como los Juegos Olímpicos y Paralímpicos se han presentado como una oportunidad única para influir y dar forma a una conciencia global”.

En efecto, los JJPP de verano Río 2016 coadyuvaron en la posibilidad de que muchos más países conocieran deportes no convencionales y adaptados, y apreciaran a deportistas paralímpicos (en adelante DP) desempeñarse a la par de los atletas sin discapacidad o convencionales (Cheong, Khoo, \& Razman, 2016). De hecho, fueron las justas de mayor difusión en la historia, llegando a 154 países a través de televisión, radio e internet y contando con 2.200 periodistas acreditados. Específicamente, el International Paralympic Committe (IPC) tuvo, al igual que en Londres 2012, el doble de visitas a su sitio web, presentando en vivo 13 deportes y los resultados de 22 (Ruiz, Riera, \& Matas, 2016). Aunque se desconoce el número de periodistas alternativos acreditados que cubrieron el evento, se sabe que cada edición hace una contribución al crecimiento de la participación de más países, la introducción de nuevos deportes, y un mayor alcance de la transmisión, incluso, de canales de medios alternativos para promocionar el evento y sus atletas (Darcy, Frawley, \& Adair, 2017).

\subsection{Medios, mediaciones y discapacidad}

Las producciones de muchos medios alternativos "son a menudo (pero no siempre) creadas por y para grupos marginados por 'raza', género, sexualidad, discapacidad o creencias", y el acceso a los medios puede ser un componente crucial de la inclusión comunitaria, la autodefensa y el empoderamiento (Valz, 
2005, p.25). De allí que sea necesario observar este tipo de periodismo en el cubrimiento de los JJPP, ya que se pueden convertir en plataforma para la modificación y ruptura de estereotipos sobre las Personas con discapacidad y la consecución de sociedades menos excluyentes.

Según Ellis y Goggin (2015), aunque existen historias, organizaciones y dinámicas específicas relacionadas con medios comunitarios, participativos o alternativos y la comunidad con discapacidad, hay poca crítica de las Personas con discapacidad sobre las bases y nociones de estos medios, así como una relativa ausencia de discusiones e investigaciones explícitas sobre la discapacidad en la literatura de comunicación comunitaria, ciudadana y alternativa. Para los autores, muchos de los medios emprendidos por incitación o con participación decisiva de Personas con discapacidad pueden considerarse proyectos de medios alternativos, ya que "la representación y la participación en las alturas dominantes de las industrias y profesiones de los medios de comunicación han resultado difíciles de obtener"1 para estas personas (p. 79). Entonces, al participar como creadores de contenidos sobre discapacidad (autorepresentación) y ser visibles en medios y organizaciones de medios, las Personas con discapacidad hacen parte de la construcción de un mundo político y cultural de "diversidad social valorada", son reconocidos como ciudadanos plenos, y crean condiciones para el cambio de actitudes, lo que se traduce en cambio social (Stewart \& Spurgeon, 2020). Aunque, por ejemplo, en la actualidad es reducido el número de Personas con discapacidad que en Australia participan en los medios comunitarios, esta implicación es más factible a través de sus propios medios.

En contraste, el papel de las mediaciones tecnológicas en las vidas de las Personas con discapacidad ha sido ampliamente estudiado, evidenciando una dicotomía entre el acceso y la accesibilidad, en la que la tecnología en línea ha ampliado el acceso a la información y a las posibilidades para hacer eco a sus propias voces y mejorar su calidad de vida, al tiempo que "ha reproducido y exacerbado las barreras ambientales que tradicionalmente excluyen a las personas con discapacidad" (Pearson \& Trevisan, 2015, p. 927). Tal es el caso de investigaciones sobre el uso de las TIC en la inclusión educativa y en la inclusión laboral / teletrabajo (recientemente en crecimiento), y de las redes sociales en función de la interacción social, la autorepresentación de las Personas con discapacidad y el activismo digital.

Con respecto a las representaciones mediáticas, Haller (1995), basada en Clogston (1990, 1993) configuró dos categorías de representación mediática de la discapacidad: la tradicional y la progresista. La primera incluye los modelos: a) médico, que la retrata como una enfermedad o un mal funcionamiento; b) patología social, que muestra a las Personas con discapacidad como menos favorecidas y que dependen económicamente del Estado y la sociedad; c)

1 Traducción propia. 
supercrip, que las presenta como súper humanas o especiales porque viven una vida normal 'a pesar' de la discapacidad; y d) de negocios, donde la sociedad accesible no es rentable, es un costo para la sociedad y las empresas en particular. De otro lado, la perspectiva progresista comprende tres modelos: e) de minorías y derechos civiles, donde la accesibilidad a la sociedad es un derecho civil y las Personas con discapacidad como comunidad cuentan con reivindicaciones políticas legítimas y derechos civiles por los que pueden luchar como los demás grupos; f) de pluralismo cultural, que resalta una atención indebida, pues no son presentadas como personas multifacéticas; y g) legal, donde los medios utilizan argumentos legales para contribuir a la erradicación de la discriminación con esta población. Al respecto, Cuesta y Meléndez-Labrador (2019) resumen que la perspectiva progresista de la comunicación aborda la discapacidad no como una condición física del sujeto, sino producto de las estructuras y dinámicas sociales que parten de matrices normalizadoras y excluyentes.

\subsection{Medios de comunicación y paralimpismo}

En cuanto al estudio de las narrativas mediáticas de discapacidad, la investigación se ha centrado exponencialmente en los medios masivos, debido al impacto que tienen estos en la construcción de un imaginario social de la discapacidad, especialmente a través del deporte, aun así autores como Bruce han desarrollado un interés por investigar "sitios alternativos a los principales medios de comunicación en los que se pueden desafiar los discursos dominantes, aumentar la visibilidad, interrumpir la comprensión dominante del género y crear y apoyar espacios alternativos para comunidades de fans" (2012, p.128). $\mathrm{Al}$ igual que Quinn y Yoshida, quienes encontraron que las representaciones de la discapacidad en medios alternativos pueden apoyar una comprensión más realista de los DP, con implicaciones positivas para las Personas con discapacidad en general, ya que cuando son representados como atletas, académicos, padres, amantes y como completamente humanos, "esto perturba los límites normativos de la humanidad y crea un espacio para nociones más amplias de inclusión"2 (Quinn \& Yoshida, 2016, p.105).

En este sentido, la evidencia científica demuestra que las imágenes mediáticas sobre discapacidad y deporte se presentan desde marcos supercrip, es decir, desde el heroísmo o un capacitismo que revalida a las Personas con discapacidad a partir de la superación de las limitaciones físicas a través del deporte. Hardin y Hardin (2004) en su estudio entrevistaron a diez DP sobre su lectura del modelo supercrip en medios deportivos y recogieron sus ideas para modelos de medios alternativos que reemplazaran un marco hegemónico y capacitado sobre las personas con discapacidad en el deporte. Los entrevistados expresaron su esperanza de modelos alternativos, pero temían que los modelos más empoderadores fueran rechazados por una cultura capacitista.

2 Traducción propia. 
Otros estudios han demostrado que existen DP que aceptan y se sienten conformes con el modelo tradicional supercrip. Hardin y Hardin (2004) consideraron que el acceso limitado que tienen a códigos de oposición y textos alternativos tiene que ver con tal aceptación, como también confirmó MeléndezLabrador (2019). Este aspecto es de vital importancia ya que evidencia un círculo vicioso de tratamiento de la información sobre discapacidad: las Personas con discapacidad consumen medios en los que son presentados desde un marco supercrip, por lo tanto lo consideran válido y no lo rechazan, lo apropian y luego replican cuando son fuentes de información sobre discapacidad. Para el caso de los DP, validan el mensaje hegemónico dominante sobre discapacidad: las historias de triunfo personal, de superación y heroísmo.

Por su parte, Hardin y Hardin (2004) encontraron que "los valores deportivos alternativos como la cooperación y la inclusión reflejarían valores sociales que deben emplearse para erradicar el capacitismo"3 (2004, p.12), aunque consideraron que existe un riesgo: la concentración en tales valores colocaría a los medios alternativos más al margen con relación al deporte que incluso lo que hace su condición de publicación sobre discapacidad. ¿Cómo se expresarían tales valores en los medios alternativos? Según los resultados de tal investigación, esto se lograría por un lado presentando imágenes deportivas de participación y no de competición; y por el otro, representando a los DP sin diferencia sexual, en igualdad de condiciones (con imágenes en acción) y de frecuencia que a los atletas hombres, aunque las mujeres participen en menor porcentaje que los hombres en los deportes. Las autoras concluyen que "las normas corporales culturales y las expectativas sociales moldearon sus expectativas, sus motivos y sus miedos. Reflejaron la fuerza de una gran presión cultural para aceptar el ideal supercrip y rechazar las ideas que podrían hacer que la sociedad rinda cuentas"4 (2004, p.12).

\subsection{Periodismo alternativo y paralimpismo}

Para el presente estudio se entiende por periodismo alternativo como aquel "que representa una opción como fuente de información, por el contenido que ofrece y por el tipo de enfoque” (Peruzzo, 2008, p. 374). Para esta autora, este tipo de periodismo se actualiza y adquiere características diferentes a partir del interés social de los ciudadanos y las organizaciones civiles en interferir en los sistemas que generan y mantienen la desigualdad, sumado a la innovación e interactividad efectiva que ofrecen las tecnologías de la información y la comunicación. Esto, teniendo en cuenta que aunque se desconoce el impacto de los medios alternativos en el movimiento paralímpico, en el caso de los olímpicos se sabe que entre finales del siglo pasado y los primeros años del presente han facilitado los esfuerzos de activistas que luchan contra la industria

3 Traducción propia.

4 Traducción propia 
olímpica en la causa de la justicia social global (Lensky, 2006). En este orden, el periodismo alternativo en el deporte paralímpico es el que se desarrolla fuera de las instituciones deportivas y de los medios masivos comerciales, y más cerca a sus protagonistas: los deportistas.

En síntesis, las investigaciones han encontrado que las narrativas sobre deporte de personas con discapacidad presentadas en medios deportivos se caracterizan por: a) presentar el marco supercrip como normal; b) priorizar al héroe (presentación hegemónica) y las historias de triunfo personal reforzando la prima capitalista del individualismo. Sin embargo, se desconoce el tipo de cobertura que hacen los medios alternativos sobre el paralimpismo y su papel en "las formas como se da voz o se amplifican voces y temáticas - por mucho tiempo acalladas e ignoradas - y como se establecen nuevas formas de participación ciudadana y comunitaria en lo que actualmente se conoce como ciberperiodismo, periodismo online, periodismo digital, web periodismo y blog periodismo" (Meléndez-Labrador, 2016, p. 214). En tal sentido, puede existir la posibilidad de que los medios alternativos sirvan de plataformas que les permitan a los DP y, por extensión a las Personas con discapacidad, desarrollar discursos contra hegemónicos y de autoreconocimiento, de tal forma que logren disgregar naturalizaciones que los excluyen y minimizan. Entonces, se estudió la hipótesis de que el periodismo alternativo sobre paralimpismo no solo construye representaciones de la discapacidad desde una perspectiva progresista sino que también alienta a una co-construcción de (auto) representaciones basadas en este modelo.

\section{Metodología}

Se realizó una investigación participativa de corte crítico-interpretativo toda vez que la investigadora estuvo inmersa en la producción de la información sobre los JJPP de Río 2016 como fotógrafa acreditada por Discomunica ${ }^{5}$, atendiendo los lineamientos de Bush, Silk, Porter y Howe (2013), y Quinn y Yoshida (2016), quienes sostienen que los esfuerzos de los académicos deben capturar las voces del atleta y su experiencia en el deporte y la discapacidad, asegurar que estas voces sean críticas, que ofrezcan espacios en los que puedan expresar y dar sentido a las experiencias de sus vidas, que creen un nuevo discurso derivado de una coalición de voces que reimagine su propio bienestar.

En ese orden, los datos fueron recolectados en un primer momento a partir de la observación participante con el objetivo de caracterizar el cubrimiento periodístico realizado antes y durante el evento; posteriormente, se analizaron los textos publicados por los medios alternativos y, finalmente, todos estos datos se contrastaron con las percepciones de los 39 DP colombianos y 6 atletas guías que participaron en Río 2016 mediante entrevistas en profundidad.

5 Ver https://www.discomunica.com 


\section{Resultados}

\section{Pre-paralímpicos}

Las mayores preocupaciones del Movimiento Paralímpico de la región y de los medios alternativos latinoamericanos especialistas en el paralimpismo fueron la falta de preparación de los periodistas deportivos en la cobertura del deporte paralímpico y el desconocimiento de la trayectoria de los atletas paralímpicos. Esto llevó a que meses antes de los JJPP 2016 se consolidara una alianza entre el Comité Paralímpico de las Américas (CPA) y periodistas expertos en paralimpismo, liderados por el medio alternativo Inspire $\mathrm{Web}^{6}$ (en adelante Inspire), con el fin de analizar las líneas de acción en Brasil y escuchar las opiniones de los DP de la región sobre lo que esperaban del cubrimiento periodístico en Río (Meléndez, 2016). Adicionalmente, escalaron este afán al ámbito académico desarrollando el Seminario Internacional de Periodismo y Paralimpismo "Nuevas narrativas de inclusión en Latinoamérica Río 2016” con el apoyo de la Asociación Colombiana de Periodistas Deportivos y la Universidad Sergio Arboleda. En este evento se buscó alfabetizar sobre paralimpismo y sobre el tratamiento periodístico de información sobre el tema.

En esta actividad se abordaron dudas sobre el marco supercrip arraigado en las prácticas periodísticas sobre discapacidad, debido a que persiste la creencia entre los periodistas de que un modelo más empoderador no llamaría la atención de las audiencias con respecto a las cuestiones sobre discapacidad. Este hallazgo coincide con lo encontrado por Hardin y Hardin (2004) sobre las presunciones que persisten en la producción de contenido mediático sobre discapacidad desde el modelo supercrip: 1. Estas historias aumentan la exposición de las Personas con discapacidad en los medios, y 2. Estas historias brindan una opinión favorable de las Personas con discapacidad.

Acerca de los contenidos, los medios alternativos Inspire, Campeones de la vida ${ }^{8}$ (en adelante Campeones) y Discomunica suministraron información valiosa que complementó el dossier de prensa emitido por el CPC. Inspire, además del desarrollo de las actividades mencionadas anteriormente, aportó una amplia y diversa videoteca con entrevistas a un grueso número de deportistas paralímpicos en su trabajo clasificatorio. Campeones también dispuso de videos pre-paralímpicos y Discomunica diseñó una campaña promocional para redes sociales con cada uno de los deportistas, presentándolos con nombre completo, disciplina, categoría y pruebas deportivas, además, contaba con una foto suministrada por el/la deportista o tomada con su aprobación (Figura 1).

\footnotetext{
6 Ver https://www.facebook.com/inspirewebcolombia/

7 Verhttps://www.youtube.com/watch?v=II7X8SgJkFoyfeature=emb_err_woyt

8 Ver https://www.fundacioncampeonesdelavida.org/
} 
Figura 1. Flyer promocional de Discomunica

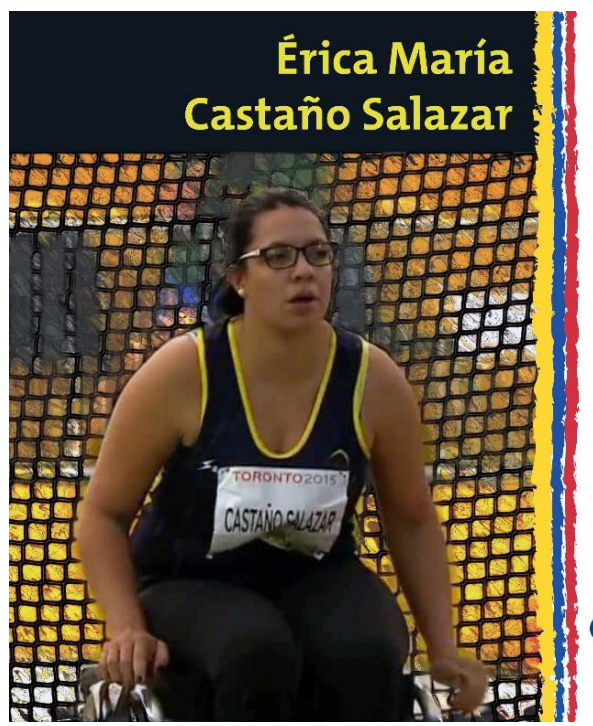

Rio2016

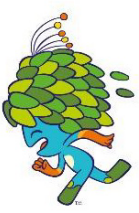

Atletismo

F55

Lanzamiento de disco

C. Lanzamiento de jabalina

\section{\#Orgullo}

Colombiano

@discomunica

Fuente: Discomunica

\section{Río 2016}

Los siguientes fueron los medios acreditados por Colombia que cubrieron el evento (Tabla 1): 1. Alternativos: Inspire ${ }^{9}$ (streaming web) y Discomunica (redes sociales y blog); 2. Oficiales/públicos: Canal Capital ${ }^{10}$ y TRO (televisión); 3. Institucionales: el Comité Paralímpico Colombiano (CPC) ${ }^{11}$ (web y redes sociales) y el actual Ministerio del Deporte (web y redes sociales). Ninguno de los medios acreditados era integrado por una Personas con discapacidad, aunque en Colombia existen medios liderados y organizados por Personas con discapacidad: Discapacidad Colombia, Urdimbre, Proclama, Norbeyo Radio y Dime Radio.

Tabla 1. Medios colombianos acreditados que cubrieron los JJPP Río 2016

\begin{tabular}{|l|l|l|}
\hline Tipo de medio & Medio & Personal \\
\hline \multirow{3}{*}{ Alternativos } & Inspire & 3 \\
\cline { 2 - 3 } & Discomunica & 1 \\
\hline \multirow{2}{*}{ Oficiales/públicos } & Canal Capital & 2 \\
\cline { 2 - 3 } & TRO & 2 \\
\hline \multirow{2}{*}{ Institucionales } & CPC & 1 \\
\cline { 2 - 3 } & Coldeportes & 2 \\
\hline
\end{tabular}

Fuente: Elaboración propia

9 Apoyado por Disnnet Prensa.

10 Apoyado por Campeones de la vida.

11 Ente que agrupa al deporte paralímpico en Colombia. 
Entre las limitaciones de los medios para producir la noticia figuraron: a) locativas: distancia entre escenarios deportivos tanto dentro como fuera de la ciudad olímpica (el estadio olímpico Engenhao utilizado para las pruebas de atletismo queda a 18 kilómetros del Parque Olímpico Barra de Tijuca); b) de personal: escaso equipo de periodistas institucionales y, en general, por medio de comunicación acreditado para Colombia que pudiera cubrir en tiempo real las participaciones de los 39 deportistas colombianos; c) económicas: ambos medios alternativos autofinanciaron su labor, por lo que debían contar con escaso personal y presupuesto; d) de derechos de transmisión: pertenecían a Claro ${ }^{12}$ por lo que ninguno de los medios realizó transmisión en vivo, si algún otro medio incumplía las normas de cobertura periodística podía perder la acreditación; e) restricciones de acceso (no aplicaban para periodistas institucionales): i) los acreditados como fotógrafos debían ocupar lugares diferentes a los acreditados como periodistas en cada uno de los escenarios, por lo tanto, los primeros tenían acceso a los campos de competición (Figura 2) y los segundos al área de prensa (Figura 3); ii) en la línea de prensa donde los deportistas atienden a los medios de comunicación al finalizar las competiciones, los fotógrafos no podían grabar video, únicamente tomar fotos y grabar audios, a diferencia de los periodistas, quienes podían grabar video pero no podían ingresar al área de fotógrafos (Figura 4); iii) no se podía fotografiar o entrevistar a los deportistas dentro de los escenarios deportivos en lugares diferentes a los antes mencionados ni en la Villa Olímpica, se debía hacer fuera de estos (figura 5); iv) algunos entrenadores impedían que los periodistas alternativos se acercaran a los deportistas para obtener sus testimonios.

Figura 2. Zona de fotografía en el estadio Engenhao

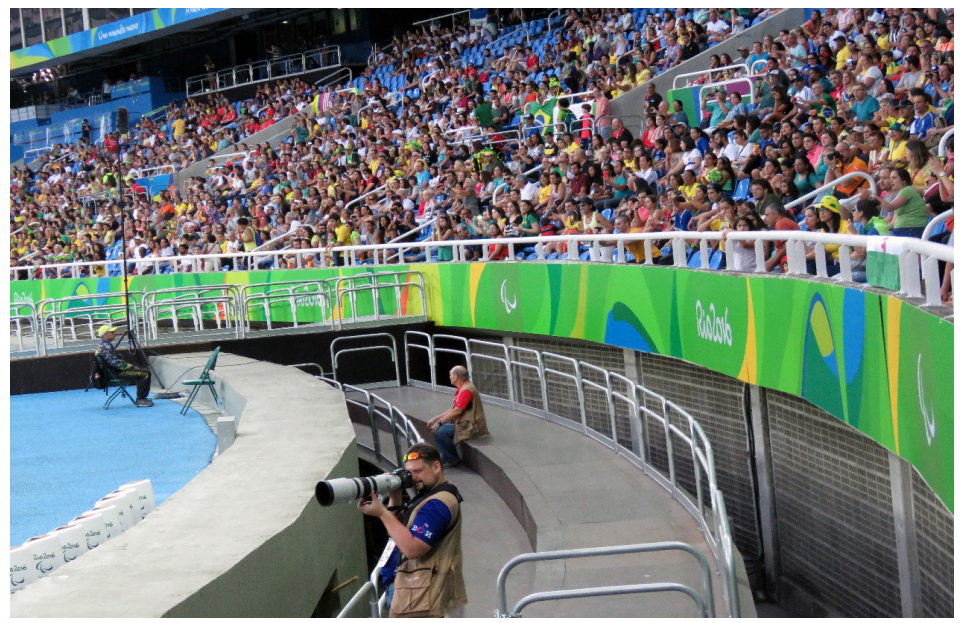

Fuente: Discomunica

12 En Colombia, la transmisión realizada por Claro no presentó todas las pruebas de los JJPP Río 2016. 
Figura 3. Zona de prensa en las piscinas de la ciudad olímpica

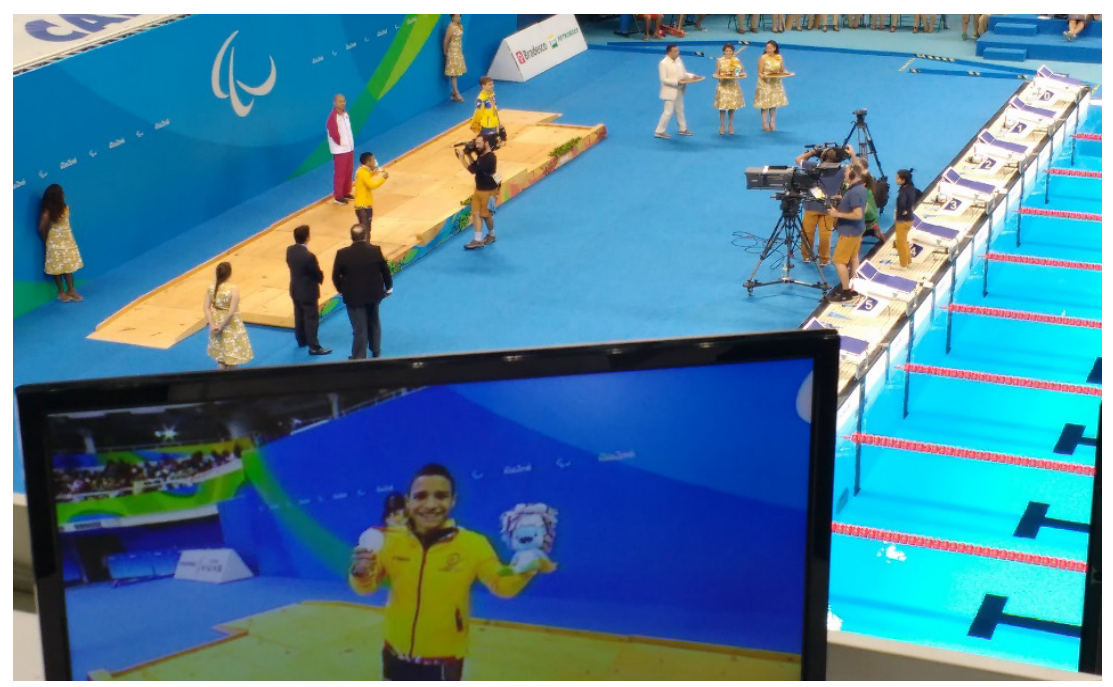

Fuente: Daniel Prieto, fotógrafo de Inspire

Figura 4. Zona de medios al finalizar competencias de atletismo

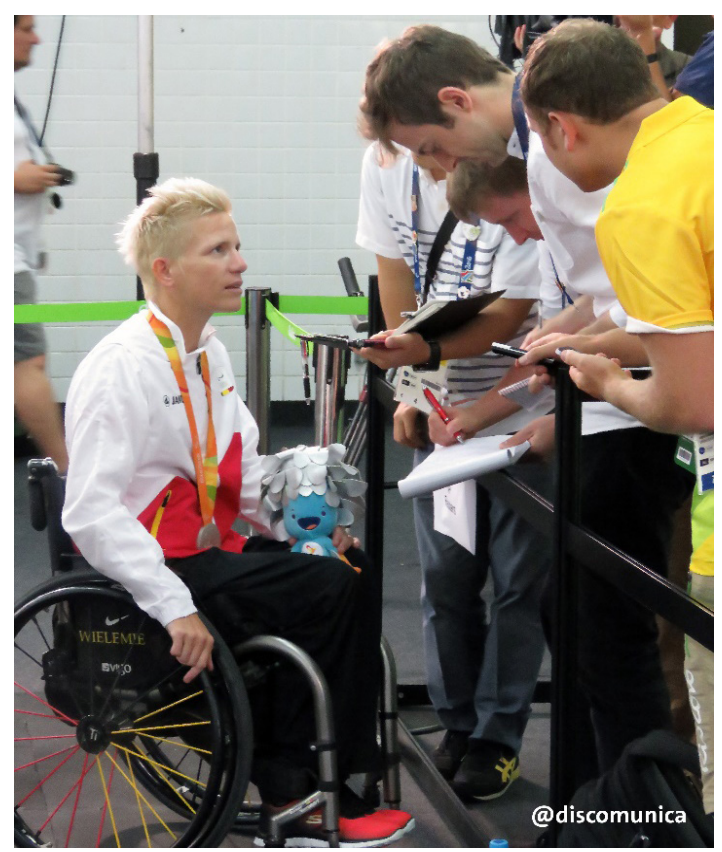

Fuente: Discomunica 
Figura 5. Inspire y el nadador Diego Cuesta a las afueras de la Villa Olímpica

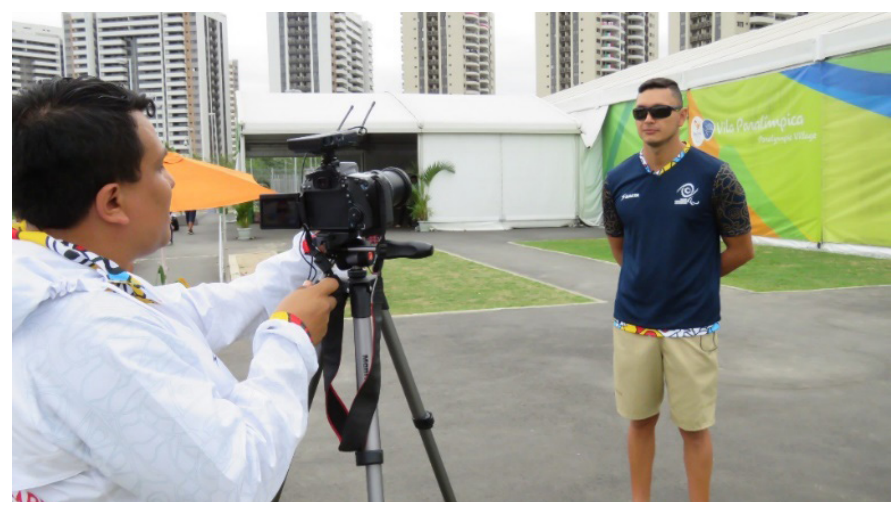

Fuente: Discomunica

Estas barreras para los medios alternativos se asocian al escaso personal y presupuesto, de allí el poco tiempo para el desarrollo de contenidos a partir de la información recolectada, sin embargo, encontraron posibilidades como: a) uso libre de imágenes tomadas por los organizadores y disponibles en una web específica (en el caso de Colombia se encontraron imágenes exclusivas de dos deportistas y que fueron compartidas); b) el IPC transmitió a través de su sitio web gran parte de las competencias que podían ser replicadas desde su canal de Youtube. En conclusión, durante los JJPP Río 2016 los medios alternativos acreditados produjeron contenidos en formato de reportaje gráfico, reportaje audiovisual, reportaje escrito y entrevista, publicados en los canales Facebook, Instagram y Sito Web/Blog (Tabla 2):

Tabla 2. Contenido publicado por los medios alternativos en los JJPP Río 2016

\begin{tabular}{|l|l|l|}
\hline Canal & Inspire & Discomunica \\
\hline Facebook & $\begin{array}{l}\text { 22 reportajes y entrevistas } \\
\text { audiovisuales }\end{array}$ & $\begin{array}{l}6 \text { reportajes audiovisuales y } \\
12 \text { galerías de fotos }\end{array}$ \\
\hline Instagram & 9 publicaciones & 20 publicaciones \\
\hline Web/Blog & & 8 reportajes escritos \\
\hline
\end{tabular}

Fuente: Elaboración propia

Pese a las limitaciones mencionadas anteriormente, los escasos medios alternativos jugaron un papel importante en la producción de las noticias que finalmente fueron publicadas en Colombia, ya que fueron una de las fuentes de fotos, imágenes y videos en el grupo en Whatsapp ${ }^{\circledR}$ creado por el CPC con los periodistas deportivos del país, canal a través del cual también el ente suministró audios de entrevistas, comunicados de prensa, programación de 
competencias, resultados, medalleros consolidados y videos de competencias $u$ otros acontecimientos. Esta intervención se debió a que los medios alternativos otorgaron mayor valor a las oportunidades de masificar el paralimpismo y los logros de los deportistas que a la exclusividad, teniendo en cuenta que parte de su trabajo complementó el del CPC al retratar a otros deportistas que no hacían parte de las predicciones como medallistas.

Por su parte, el análisis de las noticias producidas por los medios alternativos permitió caracterizarlos así: a) presentan un contexto amplio del evento: inauguración y cierre del evento, espectadores e instalaciones deportivas, ambiente exterior, opiniones de expertos; b) destacan los logros de los deportistas tanto en competición como en la premiación; c) informan sobre las participaciones de deportistas no medallistas; d) retratan la naturaleza del DP como ser humano que enfrenta miedos y derrotas; e) presentan aspectos cotidianos del DP como la concentración, el apoyo a otros deportistas, las relaciones con cuerpo técnico y familiares, la convivencia en grupo y el uso del tiempo libre; f) denuncian aspectos concernientes a la gobernanza paralímpica local, regional y global. En cuanto a las imágenes (foto y video), se encontró que tienden a promover el empoderamiento de los DP y su "espíritu atlético", ya que los presentaron cumpliendo al menos dos de las siguientes condiciones: a) en acción, b) en el campo de competición, c) con expresiones faciales compatibles con situaciones de competición, d) vistiendo ropa deportiva y e) las fotos no revelan ninguna intención de concentrarse o de ocultar la discapacidad (Pappous \& Souza, 2016) ${ }^{13}$.

Finalmente, contrastando los datos de la observación participante con el análisis textual se halló que la mayoría de los entrevistados reconocieron a Inspire como el medio líder sobre paralimpismo en Colombia y algunos valoraron su labor de denuncia acerca de las decisiones de las directivas que afectan su actividad deportiva. Asimismo, los DP consideraron necesaria la preparación en atención a medios de comunicación, pues son quienes representan al país internacionalmente y cuentan con más posibilidades de exposición mediática para visibilizar a las Personas con discapacidad. En este sentido, valoraron la labor desarrollada por Inspire en alianza con las instituciones deportivas, ya que estas actividades al ser transmitidas vía streaming y permanecer publicadas en la web garantizan el alcance a los deportistas que no son capacitados.

Los DP afirmaron sentirse satisfechos cuando las noticias incluyen su propia voz. Al respecto el paraciclista Diego Dueñas afirmó "es muy interesante cuando uno escucha una nota de voz de Río diciendo cómo me fue, cómo me sentí, si eran mis objetivos, si era lo que esperaba" (comunicación personal, noviembre 2017). Por la misma línea, los guías valoraron que los medios alternativos no los invisibilizan como suele suceder en los medios mainstream donde tienen en cuenta únicamente al atleta con discapacidad visual.

13 Esta guía impresa fue distribuida a los medios de comunicación en los JJPP Río 2016 por el Comité Paralímpico Brasilero. 
La labor de estos medios alternativos es de tal importancia que los deportistas se sienten agradecidos cuando encuentran que son los primeros, algunas veces los únicos, que los retratan, que los presentan, que los exaltan. Entre los casos figura el del triple medallista paralímpico Moisés Fuentes, quien destacó la labor de Inspire al acompañar su proceso en los JJPP de Pekín 2008, Londres 2012 y Río 2016. Otro ejemplo es el maratonista Elkin Serna, quien reconoció que gracias al periodista Juan Pablo Prieto de Inspire que lo esperaba en la meta se enteró de la medalla de plata ganada en Pekín 2008. Por la misma línea, el debutante Luis Lucumí recordó a la periodista Yaline Santos del medio alternativo DeporteNet por ser la única que lo entrevistó en la rueda de prensa pre-Río y confesó que le sirvió de aliento para lo que iba a enfrentar.

Los entrevistados coincidieron en su totalidad en avalar las imágenes positivas, de empoderamiento e igualdad tomadas por los medios alternativos, a la vez que valoraron cualquier tipo de imágenes ya que podían representar las únicas en los medios. Algunos ejemplos son las fotografías tomadas por los medios alternativos de deportistas en graderías apoyando a otros atletas o como espectadores en la inauguración del evento, o en la Villa Olímpica en su tiempo libre. Asimismo, la atleta Martha Hernández recordó que Discomunica fue el único medio que la entrevistó (Figura 6) tras convertirse en la primera medallista paralímpica colombiana. ${ }^{14}$ La atleta confesó que la foto tomada por este medio en la prueba de lanzamiento de bala les permitió a ella y a su entrenador analizar la técnica con la que compitió y los posibles errores cometidos al realizar el lanzamiento. Por su parte, la lanzadora Catalina Moreno agradeció la única foto de su participación en Río tomada por Discomunica.

Figura 6. Martha Hernández (der.), primera medallista paralímpica de Colombia

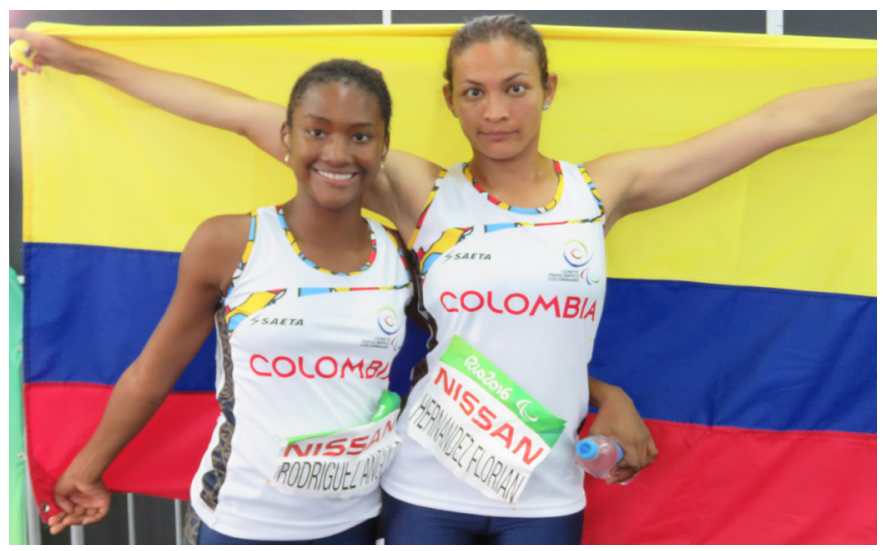

Fuente: Discomunica

14 El mismo medio suministró al CPC la imagen que el Presidente del país tuiteó con la llegada a meta del nadador ganador del primer oro paralímpico de las justas. 
En contraste, la gran mayoría de los deportistas se mostraron apáticos y renuentes, en especial aquellos deportistas cuyo desempeño en Río no fue el esperado, con respecto a rastrear su imagen en los medios, especialmente en los digitales, por lo tanto no pudieron opinar en detalle sobre lo que los medios alternativos publicaron sobre ellos. Está el caso del nadador Brayan Urbano, quien confesó "la verdad a uno le da como igual los medios de comunicación". Parte de ese desconocimiento sobre los medios alternativos que frecuentemente cubren el deporte paralímpico en el país ha llevado a DP a cerrarles las puertas, ya sea por desconocimiento de su labor social o porque prefieren atender a medios mainstream. También se encontraron los que confesaron que no les gustan los medios de comunicación porque se consideran tímidos, aun así reconocen su labor y también el deber que tienen como protagonistas de la noticia de atenderlos en las circunstancias o con el ánimo que estén. Otros se mostraron gratamente sorprendidos cuando se les comentó que la noticia que protagonizaron tenía cierto número de visitas, likes o comentarios, como sostuvo Luis Lucumí "yo estoy muy agradecido con los medios porque gracias a ellos la gente nos ve".

\section{Discusión}

En general, los medios alternativos especializados en deporte y discapacidad propiciaron una transformación en las narrativas a partir de los JJPP de Río, aunque al igual que Hardin y Hardin (2004) se encontró que persiste la imagen de héroe en algunos casos. Las autoras afirman que el modelo supercrip el estereotipo más comúnmente utilizado por los medios para retratar la discapacidad - hace aceptable la discapacidad pero solo desde un "marco de héroe discapacitado" "el cual funciona como un dispositivo hegemónico para mantener a las personas con discapacidad en la parte inferior de la jerarquía social y desviar la responsabilidad de la cultura por su infraestructura"15 (2008, p. 25).

Llama la atención la ausencia de Personas con discapacidad en los medios que cubrieron el evento, ya que su presencia en las instituciones mediáticas es también una condición necesaria para el cambio social, no solo para mejorar su representación (Stewart \& Spurgeon, 2020). Ya anteriormente Ellis y Goggin (2015) habían señalado que para desmantelar el capacitismo (valorar al sujeto únicamente por sus capacidades) era necesario garantizar la participación de Personas con discapacidad en los medios de comunicación. Esto sería superlativo en el caso de los medios alternativos, ya que buscan contribuir a una (auto) representación positiva de esta población, por lo que se hace pertinente recordar la consigna del movimiento por los derechos de las Personas con discapacidad: "Nada sobre nosotros sin nosotros".

15 Traducción propia. 
Aun con lo anterior, se encontró que estos medios pueden ser desarrollados con Personas con discapacidad aunque no hagan parte formal del mismo, en la medida que estos garantizan su participación al: 1. Dar voz ampliamente a los protagonistas en la noticia (DP); 2. Escuchar sus opiniones sobre la labor de los medios de comunicación con relación a su profesión; 3. Capacitarlos sobre la gestión estratégica de una imagen positiva de las Personas con discapacidad; 4. Propiciar la co-construcción de imágenes positivas y de empoderamiento de las Personas con discapacidad; y 5. Tenerlos en cuenta en espacios donde intervienen diversos actores para la definición de pautas de producción de información sobre ellos.

Ahora bien, los medios alternativos coadyuvan a desarrollar un proceso de alfabetización si el contenido que producen muestra al deportista primero como atleta y no como sujeto de una discapacidad, ya que este encuadre sonsaca la representación común y se centra en su rol y no en su condición, lo que genera la posibilidad de un acontecimiento formativo al trastocar los preconceptos y, en general, la matriz sociocultural que organiza su relación con la discapacidad. En efecto, siguiendo a Cuesta (2017), los medios de comunicación tienen "un potencial profundo de transformación, en la medida que puede modificar estereotipos y prácticas socioculturales sobre la discapacidad, dado que estas construcciones han sido edificadas, transmitidas y sostenidas mediante procesos comunicativos" (p. 333).

Precisamente, la participación de los DP es un elemento clave para que los medios alternativos pueden cumplir una labor transformadora en la construcción social de la discapacidad, ya que su acción directa en la producción y divulgación de contenidos permite generar condiciones para una (auto) representación mediática que contrarreste la impuesta y estereotipada (Meléndez-Labrador, 2019). Ahora bien, esto pasa para que los DP tengan un nivel de consciencia sobre las representaciones consuetudinarias que se han efectuado sobre ellos y las Personas con discapacidad, de tal modo que ellos puedan efectuar deliberada tensión a esas matrices de identidad que mantienen esquemas normalizadores.

\section{Conclusiones}

La investigación permitió evidenciar que: i) la participación de los medios alternativos en la red institucional de trabajo colaborativo facilitó una mayor visibilización de Colombia en los JJPP a través de medios masivos deportivos; ii) los DP valoraron la labor de los medios alternativos en la transformación del imaginario social sobre discapacidad y del deporte paralímpico, a partir de la democratización del conocimiento sobre el tema, la concentración de diversidad de voces y la apertura de espacios de diálogo; iii) los DP valoraron la labor (ad honorem) que realizan los periodistas de los medios alternativos, otorgando igualmente valor a los contenidos que sobre ellos generan estos medios; iv) los 
DP reconocen el aprendizaje que obtienen de los medios alternativos respecto de formas de (auto) representación que responden a una perspectiva progresista, reconociéndose partícipes de la construcción de una nueva narrativa que también intervenga el imaginario social sobre el deporte y la discapacidad.

Entonces, se puede afirmar que los medios alternativos especializados en deporte paralímpico producen y divulgan contenidos que se centran en la actividad deportiva y no en la discapacidad, al tiempo que sirven de plataforma de alfabetización de este modelo progresista de la discapacidad, no solo para otros periodistas y otros tipos de medios, sino también para los protagonistas de la información. Este rasgo permite a los medios alternativos alentar la "transformación de los estereotipos sociales que determinan creencias, actitudes y comportamientos que excluyen y minimizan a las personas que tienen cualidades y características diversas al canon instalado socioculturalmente" (Cuesta \& Meléndez-Labrador, 2019, p. 280), ya que un cubrimiento periodístico que diluye encuadres naturalizados de las DP y, por extensión de las Personas con discapacidad, permitiría modificar libretos culturales inconscientes que derivan en la clasificación, jerarquización y exclusión de los otros. Así, los medios alternativos pueden cumplir un papel transformador cuando logran co-construir contenidos que disgreguen naturalización sobre los deportistas con discapacidad, lo que resulta consecuente con la lucha por los derechos de las personas con discapacidad (Meléndez-Labrador, 2018).

\section{Referencias bibliográficas}

Bruce, T. (2012). Reflections on communication and sport: On women and femininities. Communication y Sport, 1(1-2), 125-137.

Bush, A., Silk, M., Porter, J., \& Howe, P. D. (2013). Disability [sport] and discourse: Stories within the Paralympic legacy. Reflective Practice: International and Multidisciplinary Perspectives, 14, 632-647. doi:10.1080/14623943.2013.835721

Cheong, J. P. G., Khoo, S., \& Razman, R. (2016). Spotlight on athletes with a disability: Malaysian newspaper coverage of the 2012 London Paralympic Games. Adapted Physical Activity Quarterly, 33(1), 15-32.

Clogston, J. S. (1993). Changes in coverage patterns of disability issues in three major American newspapers, 1976-1991. Paper presented to the Association of Education in Journalism and Mass Communication. Kansas City, Mo.

Clogston, J. S. (1990). Disability Coverage in 16 Newspapers. Louisville: Advocado Press.

Cuesta, O. (2017). Aportes de la comunicación para la inclusión de personas en condición de discapacidad a la vida urbana. Chasqui: Revista Latinoamericana de Comunicación, N. $\left.{ }^{\circ} 136\right), 323-336$.

Cuesta, O., \& Meléndez-Labrador, S. (2019). Discapacidad, ciudad e inclusión cultural: consideraciones desde la comunicación urbana. EURE, 45(135), 273-282.

Darcy, S., Frawley, S., \& Adair, D. (2017). The Paralympic Games: Managerial and Strategic Directions. In Managing the Paralympics (p.1-19). Londres: Palgrave Macmillan.

Ellis, K., \& Goggin, G. (2015). Disability media participation: Opportunities, obstacles and politics. Media International Australia, 154(1), 78-88. 
Haller, B. (1995). Rethinking models of media representation of disability. Disability Studies Quarterly, 15(2), 26-30.

Hardin, M. M., \& Hardin, B. (2004). The 'supercrip'; in sport media: wheelchair athletes discuss hegemony's disabled hero. Sociology of Sport Online-SOSOL, 7(1).

Hardin, M., \& Hardin, B. (2005). Performance or participation... pluralism or hegemony? Images of disability and gender in Sports'n Spokes Magazine. Disability Studies Quarterly, 25(4).

Lenskyj, H. J. (2006). Alternative media versus the Olympic industry. Handbook of sports and media, 205-216.

Martín, J. R. (2009). Observación Participante: informantes claves y rol del investigador. Nure investigación, 42, 1-4

McPherson, G., O’Donnell, H., McGillivray, D., \& Misener, L. (2016). Elite athletes or superstars? Media representation of para-athletes at the Glasgow 2014 Commonwealth Games. Disability y society, 31(5), 659-675.

Meléndez, S. (2016). Alianza latinoamericana de periodismo y paralimpismo-segundo diálogo [Mensaje en un blog]. Recuperado de https://discomunica.blogspot.com/p/alianza-latinoamericana-de-periodismo-y.html

Meléndez-Labrador, S. (2016). Periodismo alternativo y comunitario: una revisión conceptual. En Memorias del XIII Congreso Latinoamericano de Investigadores de la Comunicación. Ciudad de México: Universidad Autónoma Metropolitana.

Meléndez-Labrador, S. (2018). Formación de estereotipos sobre discapacidad, movilización ciudadana y medios alternativos. El caso de No Más Teletón en Colombia. En Memorias del XIV Congreso Latinoamericano de Investigadores de la Comunicación. Universidad de Costa Rica.

Meléndez-Labrador, S. M. (2019). De invisibles a inspiradores: autoidentificación de las y los deportistas paralímpicos colombianos en la cobertura mediática de los juegos de Río 2016. (Tesis doctoral). Universidad del Norte.

Pappous, A., \& Souza, D. (2016). Media Guide: How to cover the Rio 2016 Paralympic Games (p.1-16). University of Kent. Recuperado de https://kar.kent.ac.uk/6489o/

Pearson, C., \& Trevisan, F. (2015). Disability activism in the new media ecology: Campaigning strategies in the digital era. Disability y society, 30(6), 924-940.

Peruzzo, C. M. K. (2008). Conceitos de comunicação popular, alternativa e comunitária revisitados. Reelaborações no setor. Palabra clave, 11(2), 367-379.

Quinn, N., \& Yoshida, K. (2016). More than Sport: Representations of Ability and Gender by the Canadian Broadcasting Corporation (CBC) of the 2004 Summer Paralympic Games. Canadian Journal of Disability Studies, 5(4), 103-129.

Ruiz, A., Riera, M., \& Matas, J. (2016). Informe prensa diaria en papel de Mallorca y los Juegos Paralímpicos de Río 2016. Observatorio Medios y Discapacidad Área Familia y Discapacidad CESAG.

Stewart, K., \& Spurgeon, C. (2020). Researching media participation by listening to people with disability. Media, Culture y Society, 42 (6), 969-986.

Taub, D. E., Blinde, E. M., \& Greer, K. R. (1999). Stigma management through participation in sport and physical activity: Experiences of male college students with physical disabilities. Human relations, 52(11), 1469-1484. 